\title{
Obstáculos Epistemológicos: O Ceticismo Pirrônico
}

\author{
Sérgio Borges Nery \\ Advogado. Mestrando em Direito Constitucional. \\ Professor de Ciência Política na Universidade de \\ Fortaleza. \\ sergiobnery@hotmail.com
}

Sumário: Introdução. 1. Considerações preliminares. 2. A gênese zetética do ceticismo. 3. O telos do ceticismo pirrônico e as aparências. 4 . O ceticismo, a verdade e as refutações. Conclusão. Referências.

Resumo: Neste artigo, procura-se examinar o papel do ceticismo proveniente de Pirro de Elis, como marco fundamental da corrente filosófica que persiste até esse tempo. Inicialmente, faz-se uma passagem por conceitos genéricos da teoria do conhecimento. Em seguida, busca-se traçar os argumentos e a direção do ceticismo. Logo após, discorre-se sobre a verdade no conceito cético e delineiam-se algumas refutações. Na conclusão, faz-se uma síntese dos fundamentos do ceticismo pirrônico com a Ciência do Direito.

Palavras-chave: Ceticismo. Pirro de Élis. Entendimento humano. Direito.

\section{NTRODUÇÃO}

Este artigo se propõe a examinar as linhas gerais do ceticismo de herança do filósofo grego Pirro de Élis. O seu pensamento não legou, diretamente, uma obra escrita para análise. Todavia, Sexto Empírico, um destacado seguidor do século II a III, resgatou a obra ao escrever a H ipotiposis Pirrônicas ou, derivado da língua grega: os fundamentos de Pirro 1 . Os fundamentos do ceticismo pirrônico foram mantidos, em sua linha geral, não sendo viável, entretanto, a completa disposição dos argumentos que o ceticismo dirige às escolas que combate, nem tampouco os arrazoados empreendidos

\footnotetext{
${ }^{1}$ Hypotypoticos. Cf. nota 2, livro I.
} 
contra o pensamento de autores clássicos de orientação diversa. O presente artigo toma, pois, por base, o texto de Sexto Empírico, pelo qual busca elencar e discorrer brevemente sobre os principais vetores de atuação do ceticismo.

A crença de que o ceticismo permanece obscuro aos juristas é o móvel deste texto. Assim, após um panorama geral no primeiro capítulo, e o ingresso nos argumentos céticos primitivos - legados por Pirro - nos capítulos posteriores, a conclusão traça possíveis relações úteis ao Direito e ao motor da ciência: a dúvida.

\section{CONSI DERAÇÕES PRELIMINARES}

Antes de seguir pela trilha do ceticismo, é preciso ultrapassar algumas questões de fundo que se nos apresentam. Destas, pela relevância que importam à teoria do conhecimento, não se escapa da resposta a: i) se o conhecimento é possível; ii) qual é a sua origem; iii) qual é a sua essência; iv) qual é a sua finalidade; e v) se há um critério sólido para o conceito da verdade.

Pelo modelo de apreciação baseado na utilidade do desenvolvimento, parece certo que o objeto das inquirições sugeridas obedeça a uma sucessão paulatina, pois, não se concebe que seja, à guisa de sentença, útil ao domínio das coisas investir no exame, e.g. da essência do conhecimento, sem que antes se possa transpor a possibilidade de conhecer. O rigor da lógica formal recomenda não haver coerência em saber-se da essência de um objeto sem que, previamente, seja evidente e viva uma resposta afirmativa quanto à possibilidade. Tanto por isso, sem o prejuízo de um hermetismo inóspito, será de melhor resultado deter-se na possibilidade do conhecimento.

A Filosofia, tida como autorreflexão do espírito sobre seu comportamento valorativo teórico e prático e, igualmente, aspiração a uma inteligência das conexões últimas das coisas, a uma visão racional de mundo (HESSEN, 2003, p. 9), veicula uma relevante quantidade de informações. À matéria em discussão, o conhecimento é dependente de uma reflexão da relação filosófica sujeito-objeto que somente terá ignição com a convicção firme de que ao sujeito é viável apreender um determinado objeto. Não um sujeito qualquer o eu - tampouco um objeto geral - um particular, sob pena de ingressar no estudo da metafísica. Aos que professam que a essência de cada indivíduo seja idêntica pela igualdade de gênero, opõe-se que não há identidade de essências, pois que esta só pode ser entendida como singular, ainda que certa quantidade coincidente de qualidades os aproxime. A essência traduz uma característica natural que empreende a qualificação dos objetos encerrados em propriedades individuadoras, cuja projeção será a aparência.

Nesse diapasão, a Idade Média assistiu a um célebre acontecimento que ficou conhecido como querela dos universais. Versou o debate sobre a universalidade da essência, opondo Guilherme de Champeaux a seu pupilo Pedro Abelardo. Este reproduzia, em 
concisão que se pode ler no H istoria Calamitatum e no I ngredientibus, a afirmação do mestre pela qual:

\begin{abstract}
[.... a comunidade dos universais estabelecia que uma mesma coisa é essencial, íntegra e simultaneamente em cada um dos indivíduos, e que a diversidade destes não está em sua essência, mas unicamente na variedade de seus acidentes. Por exemplo, em todos e cada um dos homens que diferem entre si numericamente existe uma única substância do homem, que aqui, pelos seus acidentes, resulta Platão e ali, por aqueles outros, Sócrates (SARANYANA, 2006, p. 184).
\end{abstract}

Em resposta, Abelardo lançou o argumento que perpetuou-se como a doutrina do conceitualismo, ao dizer que, no mundo de um gênero, são múltiplas as espécies, que distinguir-se-ão pelas suas especificidades. Todavia, há diferenças específicas que contrariam umas as outras, disso resultando que num mesmo gênero ter-se-ia duas espécies em contradição, e.g. no gênero animal, o homem e o cavalo. O primeiro é dotado de racionalidade e o segundo irracional, logo, pelo gênero animal, aceitar-se-á que uma coisa possa ser o seu contrário (SARANYANA, 2006, p. 185). A colisão com a maior evidência da lógica - o princípio da identidade - é franca [P é P] e [P não pode ser não-P], portanto, não resistindo ao teste da lógica, deve-se orientar a direção do intelecto para a singularidade da essência.

A possibilidade de conhecer, de sua vez, propaga um dilema basilar: todo o conhecimento é possível aos homens ou, alternativamente; o homem não pode conhecer nada (MOSER, MULDER, TROUT, 2004, p. 7). A meia medida entre as duas propostas assemelhar-se-ia a dizer: posso conhecer, em certa conta, um dado número de coisas mas, uma parcela destas não se me alcança. Submetidas as três proposições à análise, verifica-se, primeiramente, que a última contradiz a si mesma, porquanto deduz implicitamente uma hierarquia de essências - umas, mais primitivas e cognoscíveis e; outras, demasiadamente complexas e incognoscíveis. Muito embora a certeza não acompanhe a forma hierarquizada das essências, é improvável que de fato ocorra, posta a sua singularidade e, decorrente dela, a impertinência de promover agrupamentos. Igualmente, não se supõe que o conhecimento humano seja capaz de apreender uma classe de objetos e exclua outra. Com efeito, os filósofos costumam acatar a posição intermediária (MOSER, MULDER, TROUT, 2004, p. 8). Quanto ao primeiro e segundo enunciados, respectivamente, os estudiosos assentem que o conhecimento tenha limite na finitude humana e; que admitir a integral impossibilidade de conhecer é, pois, uma forma de conhecimento.

A apropriação do saber é, para todos os efeitos, um dado estrutural, no meio do qual o conhecimento se edifica continuamente e as verdades são postas a prova, bem como são as conclusões submetidas a refutações. Surge daí a certeza da insuficiência material cotidiana, que corrobora não somente a tese da finitude como reafirma a aquisição de certo lugar na escala do saber. 
O desassossego natural, causado pelo abalo às fundações das certezas humanas mais comezinhas, exemplifica a magnitude do rigor a que o conhecimento se submete. Não se trata, apenas, de um rigor do conteúdo essencial dos objetos, mas, antes disso, de um rigor metodológico. Em verdade, parece ao homem que a abstração desordenada dos pensamentos conduz unicamente ao caos - lugar no qual será inviável erigir as primeiras definições de crença que pautarão todo o desenvolvimento ulterior do pensamento. De fato, o saber engendra seus desígnios por meio da certeza inabalável de um séquito reduzido de premissas. A advertência evite o fogo, é o vaticínio de um pensamento que se segue à certeza de que o fogo arde. Nesse caso, pode-se observar a existência simultânea de duas premissas. A primeira ensina que o fogo emite calor intenso, a segunda, implícita, dá a conhecer que o homem é frágil o suficiente para fazer chamuscar-se, e disso decorre uma ameaça à sua integridade. Ainda se pode opor a convicção [certeza] de que, naquele lugar, queima o fogo. Temos, pois, uma disposição ordenada de premissas mais acanhadas que, presentes no espírito e ligadas por um nexo, forcejam a determinação de uma conclusão que se crê verdadeira.

Toda plêiade de informações de que o homem dispõe precisa orientar-se por meio de uma organização que permita a correção das conclusões. Na ausência de uma definição sólida da essência das coisas, impõe-se um mecanismo de solução que possa contornar essa dificuldade. Aristóteles fez aderir aos objetos alguns predicados que buscam desimpedir o espírito na trilha do conhecimento. A tal mecanismo chamou de categorias, como modelo de enquadramento dos objetos em si e entre si, a facilitar a sua apreensão. Desta forma, para o Estagirita, são dez as categorias do pensamento: 1 . a substância; 2. a quantidade; 3. a qualidade; 4. a relação; 5. o lugar; 6. o tempo; 7. a posição; 8. a condição; 9. a ação; e 10. a passividade (ARISTÓTELES, 1964, p. 235). Evidentemente, esta disposição das categorias não sobreviveu ao tempo, encontrando em Kant um aperfeiçoamento considerável. Para o filósofo de Königsberg, as categorias aristotélicas deveriam substituir-se pelos juízos, relacionados a esta maneira: i) segundo a quantidade: universais, particulares e singulares; ii) segundo a qualidade: afirmativos, negativos e infinitos; iii) segundo a relação: categóricos, hipotéticos e disjuntivos; e iv) segundo a modalidade: problemáticos, assertóricos e apodíticos (KANT, 2003, p. 76).

O rigor metodológico a que se fez alusão é o modus da apreensão do objeto. Divide-se, classicamente, em conhecimento empírico, racional ou crítico. O empirismo é o mecanismo de conhecimento que recorre à experiência sensível; o racionalismo, por sua vez, se socorre da razão para conhecer; e o criticismo, fundado em técnica e nomenclatura exclusivas ao seu criador - Kant - é uma fusão dos dois conceitos antecedentes. Desse modo, a metodologia do conhecimento não se presta a desvendar a essência do fogo, mas cuida do método que será empregado para tal fim. 
No que toca às crenças, sem confundir-lhe com as crendices, afirma-se que subsistem a qualquer sistema que, ao insulto da complexidade dos objetos, possa-se empreender. Estas crenças não se confundem, igualmente, com os dogmatismos, pois que aquelas são razões primeiras extraídas da realidade prática que se consubstanciam em certezas medíocres, mas necessárias, e estes, afirmações cuja relação sujeito-objeto não se questiona.

\section{A GÊNESE ZETÉTICADO CETICISMO}

O ceticismo, de há muito, suscita os mais acirrados debates na Fỉlosofia. Há mesmo quem diga que se trata de tema superado pelo uso do frugal senso comum, como Moore (MOSER, MULDER, TROUT, 2004, p. 8). Não por isso, acredita-se fundamental investigar as origens do ceticismo para um primeiro contato com suas raízes.

Os estudiosos que dedicam o seu tempo à ciência acabam, de alguma maneira pelo próprio esforço, extraindo de suas investigações acerca do objeto quatro conclusões: ou bem chegando a uma descoberta; talvez resolvendo pela negação; porventura reconhecendo ser o objeto incognoscível ou; eventualmente, tirando por consequência a necessidade de prosseguir na investigação (EMPÍRICO, 1996, p. 83).

Aos que mantêm a convicção de ter chegado a uma conclusão, denomina-se dogmáticos. Para aqueles que crêem na impossibilidade de o espírito humano conhecer um objeto, instalou-se a designação de acadêmicos. Finalmente, aos que confiam os seus juízos à continuidade do exame, chamaram de céticos (EMPÍRICO, 1996, p. 83-84).

Os céticos, por sua vez, enxergam os seus propósitos como uma atividade inquisitiva, ao tempo que acreditam ser a razão de seus estudos suspensiva. No que toca ao ânimo das suas perquirições, o ceticismo revela um estado de aporia - pelo qual de tudo se duvida e se indaga, mantendo a incerteza sobre a afirmação e a negação.

Dessa maneira, chega-se a uma definição exordial do ceticismo, cuja tradução pode assim ser descrita:

[....] faculdade de opor, de qualquer modo possível, aparências e juízos, de forma que, através da equivalência entre as coisas e dos argumentos opostos, alcancemos primeiro a suspensão do juízo e, após, a imperturbabilidade (EMPÍRICO, 1996, p. 85). [traduziu-se].

Por essa definição, deduz-se que o filósofo cético será aquele que dispuser da faculdade em menção, guardando como vetor fonte o princípio da esperança em encontrar a imperturbabilidade. Mas não um estado de ânimo assemelhado à imperturbabilidade, produto da conveniência em assentir numa conclusão útil ao espírito e manancial de uma tranquilidade que não supera o confronto de argumentos contraditórios, no afã de discernir o que é verdadeiro do que é falso; mas, numa posição pela qual a cada razão que se presta opõe-se uma outra equivalente - assim entendida uma igualdade de probabilidade e improbabilidade. 
A separação é proveitosa para expor uma nota essencial ao ceticismo. Este se coloca em posição de contendor em relação ao dogmatismo que, a seu turno, não reservava a si o conceito que a atualidade lhe confere. Os acadêmicos clássicos eram filósofos que, na busca pelas verdades, concluíam por enunciados e, por essa conta, eram apontados como dogmáticos. De outro lado, os céticos não se deixavam dominar pela sedução do assentimento desarrazoado, sentiam-se, ao revés, impulsionados a não dogmatizar [na acepção de concluir]. A repulsa pelo dogma não se reputa ao entendimento lato da expressão, senão denota o desacordo em relação ao conceito pelo qual o dogma é o mais singelo assentimento a qualquer conclusão - a adesão ao entendimento não evidente. Mesmo por isso, o cético dá crédito às impressões mais simples da percepção, tais como o frio e o calor (EMPÍRICO, 1996, p. 87). A dúvida generalizada, por essa ressalva, não encontra eco nas crenças a que, previamente, aludiu-se. Em verdade, os argumentos em atenção e os desfavoráveis, juntos, anulam-se como vetores em sentido não correspondente.

Ao rechaçar o dogmatismo, os céticos pirrônicos tampouco poderiam prender-se às doutrinas de lá emanadas, por motivo bastante plausível: a doutrina, como conjunto de dogmas relacionados entre si (EMPÍRICO, 1996, p. 88), resume um modelo de atuação concorde com o assentado. Desta maneira, a doutrina colide frontalmente com as aspirações céticas, senão aquelas que, pela vivacidade da própria aparência [como as crenças], indiquem pautar-se pelos costumes e tradições, pelas leis e pelas próprias afeições.

Não por acaso, os gregos nutriam grande apego à lei, que julgavam sempre reta e justa, como legou o filósofo de Estagira (ARISTÓTELES, 1964, p. 1227) ao pronunciar que: o injusto obra contra as leis, e posto que aquele que se conforma a estas éjusto, é evidente que todos os atos conformes às leis são, deal guma maneira, justos [traduziu-se]. A vocação da lei, pelas palavras de Aristóteles, é o bem comum. Sócrates, o filósofo-rei, levou às últimas consequências o respeito às leis quando, acusado injustamente por rival - Meleto - cujo intelecto fosse mediano e o interesse na própria projeção certo, acatou o veredicto de condenação à morte pelos crimes de corrupção à juventude, descrédito aos deuses e menosprezo às leis, não sem antes dizer: Eis, portanto, que a hora de irmos é chegada, eu para a morte a qualquer tempo, vós para continuar a vida! Quem, entre eu e vós, verá o melhor destino? É por todos coisa incerta, senão à Divindade! (PLATÃO, 1959, p. 183) [traduziu-se].

\section{TELOS DO CETICISMO PIRRÔNICO E ASAPARÊNCIAS}

Os pirrônicos, como já dito, não negavam de todo a possibilidade do conhecimento, especificamente nos assuntos pertinentes ou acordes à sensação passiva - aparências. Se perguntados se o objeto guarda na sua essência as características que demonstra na aparência, os céticos acolhem o que se mostra e investem na pesquisa do que se extrai 
dela. De fato, ao investir com o raciocínio na direção da aparência, o cético tem em mira iluminar a precipitação das conclusões dos dogmáticos, jamais emudecer a aparência (EMPÍRICO, 1996, p. 90). Deste modo, fica entendido que o critério cético de orientação é o das aparências, resultado das percepções sensíveis vitais não dogmatizadas, ya que no podemos quedar completamente inactivos. As sensações passivas [aparências], no idioma grego, podem substituir-se pela grafia latina K atá phantasían pathetiken, de onde, com certa facilidade, é possível compreender que a aparência, para os gregos, está ligada à fantasia ${ }^{2}$ com todas as implicações que a semântica vernacular exibe.

O fim do ceticismo requer, antes de tudo, que se esboce não o conceito que há chegado até esses dias, mas a adoção, visando a uma compreensão mais exata, da definição cética de fim, como segue: "F in es aquello en vista de lo cual todo se hace o se piensa, ya sea por ningún otro, ya sea por el último de los objetivos apetecidos" (EMPÍRICO, 1996, p. 91). Desse modo, a finalidade do ceticismo se dirige a tudo que se faz ou pensa, excluída qualquer outra finalidade, senão meio, endereçada ao último dos objetivos desejados. Diz-se, na convergência dos princípios céticos, que o filósofo, dessa corrente aderente, visa à imperturbabilidade no opinável e a moderação no necessário. O processo mediante o qual o pirrônico filosofa acerca das percepções, no encalço de determinar-lhes a veracidade ou a falsidade para só então gozar da imperturbabilidade que almeja, deságua na equivalência dos argumentos enfileirados, cuja conclusão se acha maculada pela equânime incerteza e, não se considerando capaz de uma solução satisfatória, opta pela suspensão do juízo.

Esta imperturbabilidade, a que Pirro (EMPÍRICO, 1996, p. 92) tanto faz menção, trata da repulsa a que os céticos enxergam na emissão de juízos, posto que a carga axiológica destes direciona sempre o ânimo do investigador a formular um conceito mais genérico, de índole maniqueísta, avaliando a conclusão, em último suspiro, como boa ou má:

Pues quien estima que algo es por naturaleza bueno o malo se inquieta por todo: cuando no posee aquello que juz ga bueno, se cree atormentado por lo natural mente malo y persigue lo que supone naturalmente bueno; mas, cuando lo obtiene, se agita aún en mayor medida [...] en su temor de una mutación de la fortuna, sedesvive por completo a fin de evitar la perdida de lo que cree bueno.

Assim, as perturbações do espírito causadas pela incerteza do acerto ou do erro de juízo quanto ao objeto e, consequentemente, a apreciação deste objeto como sendo 
bom ou mau, não alcançam aos que se abstêm de formular juízos ${ }^{3}$, deixam de estimar como bom ou mau, ou não perseguem apaixonadamente coisa alguma. Com efeito, o insucesso em desvendar as contradições e relações entre as aparências e os juízos conduz ao estado de suspensão.

Muitos são os exemplos, na história da filosofia grega, que apontam para um determinado estado de ânimo das suas conclusões ou desideratos. Assim com Pitágoras, Zenão, Pirro e, mesmo, Aristóteles a respeito da amizade. A insipiência dos avanços científicos, o ambiente favorável à inscrição de novas doutrinas, o método de condução das aulas aos acadêmicos em formação e sua relação com os mestres propiciava um exacerbamento na relação deontológica dos homens com suas conclusões e favorecia o aparecimento de filosofias místicas secundárias. Daí que a evolução de teorias transbordaram, naturalmente, para ideologias e filosofias de visão do mundo com a respectiva experiência prática.

A tradição dos céticos orienta pela transmissão de dez argumentos de suspensão do juízo: primeiro, o que se refere à variedade dos animais; segundo, o das diferenças entre os seres humanos; terceiro, o das diversas conformações dos sentidos; quarto, o das circunstâncias; quinto, o das posições, distâncias e lugares; sexto, o das misturas; sétimo, o das quantidades e constituições da substância; oitavo, o da relação; nono, o da freqüência ou raridade do sucesso e; décimo, o das condutas, costumes, leis, crenças místicas e convicções dogmáticas (EMPÍRICO, 1996, p. 94-95). Por sobre estes dez argumentos, antepunham-se outros três: o de quem julga; o objeto do julgamento e; a fusão de ambos; restando estes últimos como decomposição do argumento da relação, por mais genérico, já passado em revista. É flagrante a semelhança da divisão dos argumentos com a distribuição das categorias de Aristóteles.

A propósito dos trópoi, Sexto Empírico informa que aos dez por Pirro erigidos somar-se-iam outros cinco, em sua substituição e da lavra de discípulos seus, de modo que ficaria assim a nova disposição: primeiro, o da discrepância; segundo, o do regresso ao infinito; terceiro, o da relação; quarto, o do hipotético e; quinto, o do raciocínio circular. A esta abreviação dos argumentos, coincide uma construção do pensador alemão Jakob Friedrich Fries, no seu trilema, pelo qual a tentativa do conhecimento esbarra em três conclusões pouco nobres: a do dogmatismo; a regressão ao infinito ou o psicologismo. O dogmatismo refere-se a crer num enunciado cuja validade não foi alvo de testes na medida adequada à sua validade, já o psicologismo tem como linha de frente a inclinação do investigador a universalizar o conhecimento

\footnotetext{
${ }^{3}$ Segundo $\operatorname{a~nota~}^{\circ}$ 22, Timon e Enesidemo. Os dois filósofos propunham a suspensão do juízo às indagações. Cf. EMPÍRICO (1996, p. 93).
} 
subjetivo adquirido, no mais das vezes, pela experiência e, finalmente, a regressão ao infinito afirma que a prova de uma assertiva sobre um objeto carece de nova prova que, igualmente, demanda ser provada e assim ao infinito (POPPER, 2007, p. 100113). Para Fries, todas as possibilidades de conhecimento estarão sujeitas a uma das opções por ele enumeradas, insatisfatórias evidentemente.

Antes de Fries, porém, outro filósofo recorreu à nova trópoi dos seguidores da Escola Cética, posteriores a Enesidemo: Michel de Montaigne (MOSER, MULDER, TROUT, 2004, p. 166-167). O pensador quinhentista erigiu o que ficou conhecido na epistemologia como 0 problema do critério, que deste modo revel ou-se: "Para jul gar [entre o falso e 0 verdadeiro] nas aparências das coisas, precisamos de um método de distinção; para validar esse método, precisamos de um argumento que o justifique; mas, para validar esse argumento, precisamos do próprio método em questão. E aí estamos, andando em círculos."

\section{O CETICISMO, A VERDADE E ASREFUTAÇÕES}

Para os pirrônicos, antes de pôr em marcha os esforços intelectuais com o intuito de definir um conceito sólido para a verdade, é preciso deter-se num critério de verdade. Assim, o cético terá uma atuação sucessiva pela qual, primeiramente, há de superar-se a questão do que é verdadeiro, para somente então almejar a definição de verdade. Com efeito, a verdade difere do verdadeiro em três coisas: em essência, em composição e em potência.

A distinção essencial se dá quanto ao grau de materialidade da substância de cada um dos conceitos. O verdadeiro é incorpóreo, pois incide apenas como predicativo de uma coisa - dentro do trópoi da relação - revelando uma natureza enunciativa-descritiva e de expressão discursiva; ao tempo que a verdade é corpórea, recolhendo-se em sua unidade de objeto, pois é conhecimento afirmativo de todo o verdadeiro (EMPÍRICO, 1996, p. 181).

A composição define outra distinção entre a verdade e o verdadeiro, posto que este último tem composição simples, insuscetível de adjetivações por juízos de valor, tal como dizer: eu converso. Enquanto isso, a verdade é constituída de um complexo de conhecimentos verdadeiros.

A verdade, quanto à potência, é dependente de um conhecimento virtuoso, o que não ocorre com o verdadeiro, que é autônomo. Assim, a verdade existirá apenas no homem de virtudes, capaz de um conhecimento sublimemente bom; ao passo que o verdadeiro poderá se fazer presente no homem mau, já que contempla-se a possibilidade deste expressar algo de verdadeiro (EMPÍRICO, 1996, p. 181).

A verdade será, então, definida como um sistema de conhecimento das coisas verdadeiras. Nesse passo, a verdade, como reflexo de algo incognoscível, não se transforma no objeto de refutação e, mesmo, de investigação do cético; mas o verdadeiro, pela carga discursiva que representa sem a devida repercussão material de 
evidência que deveria trazer. O canhoneio dos pirrônicos, a essa altura, volta-se aos sofistas, ao pretenderem derrubar as premissas maiores de seus argumentos e, a partir daí, arruinar todo o edifício de conhecimento dogmático destes, pois:

[....] quem diga que algo existe não será, dada a discrepância, acreditado sem demonstração; e se pretende oferecer demonstração, não se lhe abonará se admite que é falsa, mas se a afirma verdadeira, incorrerá no raciocínio circular e se lhe exigirá apresentar demonstração da existência de uma verdadeira demonstração, e outra daquela, e assim ao infinito. Mas é impossível fazer infinitas demonstrações: logo impossível também saber que existe algo verdadeiro. (EMPÍRICO, 1996, p. 182). [traduziu-se].

Aparece, ainda na esteira da verdade, um argumento clássico da autocontrariedade da afirmação universal da falsidade: tudo é falso, significa que o interlocutor pretende afirmar como verdadeiro que tudo é falso, formando assim uma contradição insuperável em si mesma. Nada é falso, implica em dizer que o nada é alguma coisa [falso], dando uma existência ao nada que, com isso, deixa de ser alguma coisa [nada]. O nada não pode ser algo. À afirmação: tudo é verdadeiro, segue-se que nada é falso, incorrendo na contradição precedente, bem como suspendendo o juízo sobre a natureza de correspondência das coisas - o que reforça os princípios céticos. Ao cabo, se a afirmação: tudo é verdadeiro e falso for correspondente ao mundo dos objetos, ter-se-á que as coisas serão verdadeiras e falsas, particularmente, a um só tempo, donde se extrai que nada há de verdadeiro, pois contém em si a falsidade.

Não sendo possível, então, à verdade ser verdadeira, necessário se faz uma reformulação do conceito de verdade, ou a suspensão do juízo a esse respeito. A par da aceitação dos pirrônicos de um conhecimento sensível primitivo, a colocação da epistéme não salva aos homens; apenas a dóxa, ou a matéria opinável.

Todavia, não foram poucas as tentativas de superar os conceitos céticos, tidos como obstáculo formal ao desenvolvimento do conhecimento, antes critério depurador de coerência metodológica.

Ainda na antiguidade, Górgias (VASCONCELOS, 2000), mesmo sem travar contato com o ceticismo pirrônico, antecipava crítica mordaz ao fundamento do cético: como poderíamos saber que encontramos o que procurávamos, se, com antecedência, já não soubéssemos o que estávamos procurando.

George Berkeley, em 1713, dá a publicar os T rês D iálogos entre H ilas eF ilounous em oposição aos céticos e ateus, no qual, em seu Primeiro Diálogo, Filounous interpela H ilas com o pedido de que este lhe diga o que entende por cético, por ter sido assim apontado ao negar que a matéria tenha existência, no que responde e prossegue:

H.: O que toda gente: entendo alguém que duvida de tudo.

F.: O que não duvida, por conseguinte, acerca de um ponto particular, pelo que tange a esse ponto não pode ser dito um cético. 
H.: Com isso eu vou.

F.: Consiste o duvidar, porventura, em tomar a solução afirmativa ou a solução negativa de uma questão?

H.: Não; em nenhuma das coisas; para quem quer que perceba o falar inglês, duvidar significa uma suspensão entre as duas.

F.: Logo, do indivíduo que nega um ponto qualquer não se pode dizer que duvida dele - nem mais nem menos do que de quem o afirma com o mesmo grau de segurança.

H.: Assim é, de fato.

F.: Por conseguinte, ao primeiro, lá porque nega, não o teremos por mais cético do que ao segundo.

H.: Reconheço que sim.

F.: Como então, ó Hilas, vos ocorre pronunciar que sou eu um cético, só porque nego o que é por vós afirmado, ou seja, a existência da matéria? Já que, como quer que digais, sou tão peremptório na negação como vós o sois no afirmar. (BERKELEY, 1980, p. 50).

Filounous desvenda a Hilas o erro de apontar o cético como agente de toda a negação, enquanto Berkeley tem em vista provar o conhecimento empírico, em oposição ao ceticismo radical para o qual a experiência não forneceria dados de apreensão mediata, apenas imediata.

Georg Wilhelm Friedrich Hegel (apud HESSEN, 2003, p. 44), formulou a seguinte objeção, nos termos que seguem:

A investigação do conhecimento não pode ocorrer senão conhecendo; investigar esse assim chamado instrumento não significa outra coisa senão conhecê-lo. Mas querer conhecer antes de conhecer é tão incongruente quanto a sábia resolução daquele escolástico - aprender a nadar antes de aventurar-se na água.

A objeção de Hegel, com efeito, não repercute no sistema pirrônico, haja vista que o ceticismo antigo admite certa quantidade de conhecimento, como já demonstrado.

Donald Davidson opõe o Princípio de Caridade ao ceticismo. Por este princípio, que veicula uma das modalidades contemporâneas de crença - as que se ligam ao conhecimento mais comezinho, de utilidade prática - deve-se aceitar inicialmente como verdadeiras as afirmações dos interlocutores porquanto as diferenças culturais, que distanciam estas pessoas do ouvinte, são tendentes a criar um conhecimento estranho às faculdades intelectuais originárias, donde a prevalência será governada pela boa-fé, interesse em conhecer e na boa vontade de compreender o outro. Desse modo, o interlocutor estará colocado numa posição de equivalência ao ouvinte, de modo que seus argumentos não sejam, prima facie, invalidados (MOSER, MULDER, TROUT, 2004, p. 52-53). 


\section{CONCLUSÃO}

O ceticismo, desde as suas mais longínquas raízes, mantém-se vivaz pelo fato de lidar com um desafio que, a um só tempo, atormenta e anima a alma da humanidade a possibilidade do conhecimento. A dúvida, que ensejou uma das diretrizes cartesianas, permanece à sombra de tudo o quanto se possa produzir no saber. E bem que assim seja, pois o espírito alerta não habita o erro primário, senão traz à ciência um ciclo de conjecturas, e novas conjecturas a substituir as antecedentes, e por esta via segue.

O Direito encontra no ceticismo grave barreira a ser vencida, de vez que aquele atua, eminentemente, segundo as diretrizes da dialética - lugar da oposição da tese e da antítese, com vistas a extrair do processo a síntese. O ceticismo define a contrariedade de argumentos conducente a uma recíproca anulação, nos moldes da sobreposição vetorial dos geômetras, e a indefinição marcada pela incerteza leva o juízo pautado pelo ceticismo não a concluir ou sintetizar, mas, a suspender o juízo. Talvez pelo temor aos céticos, o pragmatismo que marcou os romanos antigos tenha legado o adágio proibitivo, célebre, que caracteriza a jurisdição: Non liquet.

Também a imperturbabilidade cética incide no Direito quando a este se imputa o caminho para a justiça. A prolação de uma sentença judicial, em litígio, há sempre que posicionar uma perda e um benefício aos jurisdicionados, ainda que originariamente pertencentes a vantagem e o desfavor aos mesmos, não chegará a firmar a convicção da justiça feita. O idêntico argumento é utilizado pelos apóstolos da mediação extrajudicial.

As relações do Direito com a ontologia, muito embora de pouco costume, são fundamentais para traçar as regras deontológicas que se pretenda. Não é a intenção, neste momento, de emitir juízo de valor quanto ao conteúdo da positivação, mas, mesmo adotada a orientação da validade do direito natural, os conceitos por este talhados hão de servir-se da essência dos objetos ali compreendidos. Tanto por isso, o ceticismo interessa ao Direito por sobressaltar o espírito do jurista e pôr em dúvida as suas definições mais primordiais. Igualmente, as verdades sobre as quais o Direito erige todo o seu sistema, se abaladas, tendem a fazer ruir a estrutura de um edificio que se constrói a mais de dois mil anos, quiçá para redefini-lo como dogmático, porquanto, ao desencontro das outras ciências, o Direito goze de uma vasta estabilidade conceitual. Resta a advertência dos pirrônicos: a razão das aparências é precária e a essência das coisas, insondável.

\section{REFERÊNCIAS}

ARISTÓTELES. Etica Nicomaquea. Madrid: Aguilar, 1964.

Lógica. Madrid: Aguilar, 1964.

Política. Madrid: Aguilar, 1964. 
BERKELEY, George. Três Diálogos entre Hilas e Filounous em oposição aos céticos e ateus. 2. ed. São Paulo: Abril Cultural, 1980.

EMPÍRICO, Sexto. Hipotiposis Pirrónicas. Madrid: Akal, 1996.

HESSEN, Johannes. Teoria do conhecimento. 2. ed. São Paulo: Martins Fontes, 2003.

KANT, Immanuel. Prolegómenos a toda a metafísica futura. Lisboa: Edições 70, 2003.

MOSER, Paul K.; MULDER, Dwayne H.; TROUT, J. D. A Teoria do Conhecimento: uma introdução temática. São Paulo: Martins Fontes, 2004.

PLATON. Apologie de Socrate. v.1. Paris: Gallimard, 1959.

POPPER, Karl R. A lógica da pesquisa científica. 1. ed, 13. reimp. São Paulo: Cultrix, 2007.

SARANYANA, Josep-Ignasi. A Filosofia Medieval: Das origens patrísticas

à escolástica barroca. São Paulo: Instituto Brasileiro de Filosofia e Ciência "Raimundo Lúlio", 2006.

VASCONCELOS, Arnaldo. "Que é uma teoria jurídico-científica?". Revista da OAB/ CE. Fortaleza: ano 27, $\mathrm{n}^{\circ}$ 4, julho-dezembro/2000.

\title{
EPISTEMOLOGICAL EMBARRASSMENT: PYRRHONIAN SKEPTICISM
}

\begin{abstract}
Analysis of the role of skepticism originated in Pyrrus of Élis, as a landmark in this philosophical arena, keeped alive until our days. At the beginning, general concepts of the human understanding theory are focused, then to the skepticism arguments and direction. Thereafter, the truth in skepticism boundaries is discussed, as well as the outline of some refutation. At the very end, a synthesis is made based on Pyrrus skepticism and Law Sciences.
\end{abstract}

Keywords: Skepticism. Pyrrus of Élis. Human understanding. Law. 